\title{
O fim do uso do alojamento nos grandes canteiros de obras de São Paulo como instrumento de flexibilização do trabalho
}

\author{
Marcus Vinicius Spolle*
}

O alojamento dentro dos canteiros de obras da construção civil foi apontado por Sonia Grandi (1985), em sua pesquisa sobre mobilidade da força de trabalho na construção civil, como fator migratório importante: de um lado, estratégia de sobrevivência do migrante na metrópole e, de outro, fator de atração e barateamento da mão de obra para o empresário, instrumento de redução de custos.

A partir de 1998, porém, foi constatado, através de pesquisa feita nos canteiros de obras da construção civil ${ }^{1}$, que o alojamento passou a não ser mais utilizado com frequência pela indústria da construção civil, principalmente no setor de edificação habitacional, comercial e administrativa da cidade de São Paulo, ficando restrito a áreas onde não existiam infraestruturas urbanas, como: construção de estradas, pontes e viadutos; locais afastados dos grandes centros; obras e reformas feitas por pequenas empresas de construção civil nas áreas periféricas da capital paulista.

Essa mudança reflete mais que o fim de uma estratégia, dentre as inúmeras utilizadas pelo capital para desonerar custos, representando, na verdade, um novo paradigma nas formas de acumulação, o que vem sendo caracterizado como acumulação flexível ${ }^{2}$.

\section{Sobre a pesquisa}

Dado o grande volume de construções na cidade de São Paulo, a pesquisa realizada partiu da definição de uma amostra que pudesse dar conta da utilização

* Doutor em Sociologia pela UFRGS. 
do alojamento na construção civil na cidade. Para tanto, foram utilizados, num primeiro momento da pesquisa, os dados cadastrados e disponibilizados pela SEHAB/SP (Secretaria de Habitação da Prefeitura Municipal de São Paulo), referentes ao número de canteiros de obras de edificação habitacional, comercial e administrativa nas Administrações Regionais do município de São Paulo.

Escolhida esta fonte de dados, foi necessário estabelecer um corte temporal e outro espacial para a abordagem da questão. O período escolhido para a análise foi o dos três anos retroativos ao início da pesquisa $(1998,1997,1996)$. Tal procedimento justifica-se em função do tempo máximo concedido para se dar início à obra: três anos. Assim, para os anos anteriores a 1996 não poderiam ser encontrados canteiros de obras, pois o prazo do alvará já teria expirado ou a construção já teria chegado ao seu término ${ }^{3}$.

O corte espacial baseou-se na divisão do município de São Paulo em Administrações Regionais - ARs. Cada Regional é formada por um conjunto de distritos. A cidade de São Paulo tem 96 distritos, distribuídos em 28 Administrações Regionais. Foram selecionadas as Regionais onde o conjunto de distritos apresentou maior crescimento, isto é, uma verticalização intensa no período de 1991 a 1995, com números de construções situados entre os mais elevados: AR/Moóca e AR/ Pinheiros.

Para conseguir identificar as Regionais com maior crescimento vertical, recorreu-se aos índices de verticalização, no período de 1991 a 1995, nos distritos da cidade de São Paulo. A metodologia para a elaboração do índice de verticalização foi desenvolvida pela Secretaria de Planejamento do Município de São Paulo. $O$ índice indica a participação da área verticalizada em cada distrito.

É importante salientar que as bases espaciais utilizadas pela Secretaria de Habitação e pela Secretaria de Planejamento não são as mesmas. A primeira divide a cidade em Regionais, enquanto a segunda trabalha com a divisão distrital. Embora as Regionais sejam compostas por distritos, não existe coincidência perfeita entre as duas bases. Isso porque alguns distritos têm sua área dividida entre duas Regionais vizinhas.

A partir do índice de crescimento vertical na cidade de São Paulo, foi escolhida a AR/Pinheiros, por ser a segunda Regional com o maior crescimento (2.273.841 $\left.\mathrm{m}^{2}\right)$ no índice de verticalização no período estudado, ficando somente atrás da Regional Vila Mariana $\left(2.296 .283 \mathrm{~m}^{2}\right)$. Como esta Regional teve índices negativos de crescimento nos setores comercial e de serviços nesse mesmo período, deuse preferência à Regional Pinheiros.

Já a AR/Moóca foi escolhida por ser uma das Regionais que tem os maiores índices de crescimento vertical $\left(762.892 \mathrm{~m}^{2}\right)$. Está entre as dez primeiras. Além disso, os distritos do Tatuapé e Moóca localizam-se na Zona Leste da cidade, oposta à Regional Pinheiros, localizada na Zona Oeste, a outra escolhida. Enquanto corte espacial, é uma tentativa de cobrir uma extensão maior da cidade; além de permitir a comparação de Regionais com características sociais diferentes. 
A partir desta seleção, foram listados os endereços dos canteiros de obras contidos no cadastro da Secretaria de Habitação, referentes a essas duas Regionais, que haviam obtido autorização para iniciar a obra. Esses foram localizados na Planta da Cidade de São Paulo e visitados.

Verificou-se que, na maioria dos locais, as obras estavam em andamento. Apenas em dois canteiros as obras ainda não tinham sido iniciadas.

\begin{tabular}{|c|c|c|c|c|c|}
\hline \multicolumn{6}{|c|}{ Tabela 1: Alojamentos nos canteiros de obras por regional: 1996 a 1998} \\
\hline Regionais & $\begin{array}{c}\text { Sem } \\
\text { alojamentos }\end{array}$ & $\begin{array}{c}\text { Com } \\
\text { alojamentos }\end{array}$ & $\begin{array}{c}\text { Obras } \\
\text { finalizadas }\end{array}$ & $\begin{array}{c}\text { Obras não } \\
\text { iniciadas }\end{array}$ & Total \\
\hline $\mathrm{AR} / \mathrm{PI}$ & 67 & 01 & 02 & 01 & 71 \\
\hline $\mathrm{AR} / \mathrm{MO}$ & 62 & 00 & 01 & 01 & 64 \\
\hline Total & 129 & 01 & 03 & 02 & 135 \\
\hline
\end{tabular}

Fonte: Spolle, 2001.

A Tabela 1 foi elaborada a partir das visitas aos canteiros de obras das Regionais selecionadas (AR/Moóca e AR/Pinheiros). Da análise dos dados pôdese concluir que, considerando-se as duas Regionais, dos 135 canteiros visitados, em 129 não havia alojamentos, o que significa 95,5\% do total dos canteiros.

Na Regional Pinheiros foram visitados 71 canteiros. Desses, em 67 (96,8\%) não havia alojamento, 2 já haviam terminado a fase de construção e em um as obras não tinham sido iniciadas. Na única obra em que foi constatada a utilização de alojamento, a empresa responsável pela alocação dos trabalhadores fornece alojamento fora do local de trabalho: a empresa aluga uma casa nas proximidades do canteiro. Único caso encontrado, não parece esboçar uma nova tendência, tendo sido, aqui, tratado como exceção.

Já na Regional Moóca foram visitados 64 canteiros e em nenhum deles foi constatada a presença de alojamento. Uma das obras já estava concluída e outra ainda não havia sido iniciada.

É importante ressaltar que as obras de pequeno porte não foram arroladas. As pequenas empresas do setor da construção que, geralmente, trabalham com a construção ou reforma de casas, além de estarem vinculadas, enquanto autorização da obra, à Administração Regional e não à SEHAB, estão dentro da lógica do mercado informal, o que dificulta uma análise comparativa sobre as estratégias de utilização de instrumentos de exploração e aliciamento da força de trabalho em setores tão díspares.

Assim, as conclusões sobre o fim do alojamento estão delimitadas a uma fatia do subsetor da construção civil, isto é, o das grandes empresas que constroem prédios habitacionais, comerciais e administrativos na cidade.

As informações dadas pelos responsáveis pelas obras (engenheiros ou mestres de obras) confirmam a tendência para o fim do alojamento, atestando que, nos anos 1997 e 1998, as empresas não utilizavam mais esse expediente. Os alojamentos faziam-se presentes somente na periferia da cidade (na construção de viadutos e pontes, por exemplo) ou na construção de estradas. 
Assim, foi constatado, na pesquisa, que esse tipo de moradia não era mais a "porta de entrada" para o trabalhador migrante recente, obrigando a questionar sobre os motivos que levaram ao fim do uso dessa estratégia por parte dos empresários.

Para investigar esta questão do fim do alojamento, foram entrevistados os representantes dos sindicatos patronais e dos empregados da construção civil, que confirmaram a tendência.

\section{Sobre o fim dos alojamentos}

A análise dos indicadores sobre emprego e desemprego na cidade de São Paulo, na segunda metade da década de 1980 e na década de 1990, possibilita a compreensão das estratégias do setor:

\begin{tabular}{|l|r|r|r|r|r|r|r|r|r|r|r|}
\hline Tabela 2 - Distribuição do Pessoal Ocupado segundo Setor de Atividade Econômica (1985 a 1998) \\
\hline Setor de Atividade & \multicolumn{2}{|c|}{ Distribuicão do Pessoal Ocupado (\%) } \\
\hline & $\mathbf{1 9 8 5}$ & $\mathbf{1 9 8 6}$ & $\mathbf{1 9 8 7}$ & $\mathbf{1 9 8 8}$ & $\mathbf{1 9 8 9}$ & $\mathbf{1 9 9 0}$ & $\mathbf{1 9 9 2}$ & $\mathbf{1 9 9 4}$ & $\mathbf{1 9 9 6}$ & $\mathbf{1 9 9 8}$ \\
\hline Indústria de transf. & 29,8 & 31,4 & 30,9 & 29,1 & 30,4 & 28,3 & 24 & 23,4 & 20,8 & 17,8 \\
\hline Construção Civil & 3,0 & 3,3 & 3,7 & 4,1 & 3,7 & 3,2 & 2,9 & 2,8 & 2,7 & 2,4 \\
\hline Comércio & 14,7 & 14,6 & 15,2 & 14,9 & 15,0 & 16,8 & 16,6 & 17,1 & 17,4 & 17,0 \\
\hline Serviços & 44,0 & 42,4 & 42,8 & 44,4 & 44,1 & 45,1 & 48,5 & 48,9 & 50,8 & 54,1 \\
\hline Serviços Domésticos & 8,1 & 7,8 & 7,0 & 6,8 & 6,1 & 6 & 7,3 & 7,3 & 7,8 & 8,3 \\
\hline Outros & 0,2 & 0,3 & 0,3 & 0,3 & 0,3 & 0,4 & 0,5 & 0,3 & 0,3 & 0,3 \\
\hline Sem Declaração & 0,2 & 0,2 & 0,2 & 0,3 & 0,4 & 0,4 & 0,2 & 0,2 & 0,1 & 0,1 \\
\hline Total & 100 & 100 & 100 & 100 & 100 & 100 & 100 & 100 & 100 & 100 \\
\hline
\end{tabular}

Fonte: Fundação SEADE; Pesquisa Emprego e Desemprego.

No primeiro período (1985 a 1989) da Tabela 2, verificou-se que o setor da construção civil teve um aumento no índice de ocupação, isto é, o setor estava em expansão, o que pode indicar que as estratégias de contratação, via alojamento, faziam parte dos instrumentos utilizados pelas construtoras, o que foi ratificado pelo estudo de Sonia Grandi. A autora apontava o alojamento como "porta de entrada do migrante".

Já na década de 1990, os índices de ocupação do setor da construção civil começam a mostrar um pequeno declínio. Este fato, somado a outros, como o desemprego, a recessão, a adaptação ao mercado e a modernização da indústria da construção civil, podem ter sido responsáveis pelo fim do uso do alojamento nos canteiros de obras.

A partir da análise dos dados e das entrevistas, foram levantadas algumas hipóteses que explicariam o fim do alojamento. A primeira delas é que esse fenômeno seria efeito do processo de recessão e desemprego estrutural, principalmente como reflexo do novo paradigma nas formas de acumulação do capital, marcado pela globalização e pelas políticas econômicas neoliberais. Um excedente de trabalhadores residindo nas cidades foi sendo gerado, o que garantiria a demanda de força de trabalho, de tal maneira que o alojamento 
não fazia mais sentido como instrumento de atração da mão de obra migrante. Porém, esta hipótese pode ser descartada, pois a pesquisa nos canteiros de obras também evidenciou a existência da continuidade do uso de migrantes recentes ${ }^{4}$ pela indústria da construção civil, apesar do fim do uso do alojamento.

Esta importante constatação levou a uma segunda hipótese: o setor continuou valendo-se das vantagens sobre o custo da força de trabalho oferecidas pelo uso do trabalhador migrante, porém, desonerou-se do custo do alojamento como forma de manter os lucros, mesmo em um período recessivo, não tendo de arcar com o custo da moradia, deixando para o migrante essa responsabilidade.

Assim, com o fim do alojamento, o empresário do setor da construção civil continuou utilizando o migrante recente sem os incômodos decorrentes do uso desse tipo de moradia.

Outra questão, que se somaria à segunda hipótese, no sentido de novas estratégias para diminuir o custo da produção, seria a levantada a partir das entrevistas realizadas com os representantes dos sindicatos, tanto patronais como dos trabalhadores, que apontam a alteração da Norma Regulamentadora n.o 18 (NR 18) - Condições de Meio Ambiente de Trabalho na Indústria da Construção, sancionada em 26 de julho de 1983. Os estudo que embasaram essa alteração foram iniciados a partir de determinação do Serviço de Saúde e Segurança do Trabalho do Ministério do Trabalho (SSST/MTb), em 10 de junho de 1994. Em 7 de julho de 1995 foi publicada, no Diário Oficial da União (DOU), a alteração da mencionada Norma Regulamentadora.

Segundo a justificativa dada no prefácio da publicação, a alteração foi motivada pela necessidade de atualização diante das reivindicações do sindicato e de instituições ligadas à seguridade do trabalhador da construção civil, além da evolução dos métodos, avanços da tecnologia e das relações de trabalho do setor.

As alterações havidas quanto às condições de segurança e salubridade nos alojamentos, na opinião dos sindicalistas representantes dos operários da construção civil pública (COHAB e CDHU), constituíram fator decisivo para o fim dos alojamentos. A Legislação, em seu item 18.4.2.10, referente à questão do alojamento, prevê:

(...) os alojamentos dos canteiros de obra devem ter paredes de alvenaria, madeira ou material equivalente; ter piso de concreto, cimento, madeira ou material equivalente; ter cobertura que proteja das intempéries; ter área mínima de $3,00 \mathrm{~m}^{2}$ por módulo cama/armário, incluindo a área de circulação; ter área de ventilação de, no mínimo, 1/10 da área do piso; ter iluminação natural e/ou artificial; não estar situado em subsolos ou porões das edificações; ter instalações elétricas adequadamente protegidas; uso de, no máximo, 2 (duas) camas na mesma vertical; ter armários duplos individuais (...) (DOU, 1995). 
Ainda segundo os sindicalistas, essa alteração teve influência no custo da manutenção do alojamento e, por decorrência, no custo da força de trabalho, resultando, assim, no fim desse instrumento de arregimentação como forma de barateamento da mão de obra. Tanto assim que grandes empresas (Camargo Corrêa, CBPO, etc.), que sempre investiram em salário indireto, como cesta básica, alojamento e refeitório, estavam aos poucos desistindo do uso da moradia no local de trabalho. Como as outras empresas não adotaram o mesmo procedimento, em termos de concorrência de mercado, o custo da força de trabalho tornou-se inviável.

Todavia, apesar do fim do alojamento ser um efeito das alterações da NR18 , não se pode concluir que tal medida seja o reflexo da decisão de cortar o custo, de maneira isolada. Essa medida é mais um componente do processo de desregulamentação, terceirização e precarização do trabalho, resultado das novas relações entre capital e força de trabalho preconizadas no contexto da chamada acumulação flexível.

Além do fim do alojamento, é cada vez mais frequente o uso de outros artifícios de barateamento da força de trabalho, como a terceirização: prestadoras de serviços que contratam a mão de obra ou cooperativas que utilizam trabalhadores sem ter os custos trabalhistas.

Os motivos do fim do alojamento e do uso de outros instrumentos de aliciamento, barateamento e precarização da força de trabalho fazem parte das transformações ocorridas na relação entre capital e força de trabalho nas últimas décadas, principalmente vinculadas ao processo de globalização iniciado a partir do final dos anos 1980.

A partir desse período, as transformações tecnológicas, como a revolução da microeletrônica, põem fim ao padrão fordista de produção, resultando na mudança das relações entre capital e trabalho, tais como os processos de terceirização, flexibilização e desregulamentação da força de trabalho.

Segundo Robert Kurz, o sistema produtor de mercadorias esgotou a sua possibilidade de crescimento dentro da lógica fordista/taylorista, esbarrando na contradição entre o imenso desenvolvimento tecnológico e a manutenção da base de consumo. Assim, o mercado começa a se tornar saturado. Com o advento da revolução tecnológica da microeletrônica, é dado o salto no crescimento que irá refletir como crise de geração de empregos nos anos 1980. Sem uma base nacional que garanta o consumo, faz-se necessária, por um lado, a expansão transnacional, isto é, o processo de globalização e, por outro, a mudança da lógica produtiva, agora flexível. Essas transformações implicam na alteração da lógica das políticas estatais e do próprio Estado; o neoliberalismo e a "invenção" do Estado mínimo vão garantir a desregulamentação dos direitos trabalhistas e o baixo custo da força de trabalho, tanto nos países centrais como na periferia, pois o capital globalizado e sem pátria agora busca produzir onde o custo da produção é baixo - salários, matéria-prima ou infraestrutura (KURZ, 1995). 
Dentro desta lógica de racionalização, a forma de produzir do sistema produtor de mercadorias também se modifica com a flexibilização da produção. A flexibilização faz-se em vários sentidos: flexibilidade dos produtos frente às necessidades do mercado; flexibilidade do trabalhador, que se torna polivalente, "um homem, cinco máquinas"; a flexibilidade da força de trabalho frente à terceirização e à desregulamentação do trabalho. Desse modo, o sistema produtor de mercadorias tende a utilizar todas as formas para baratear o custo de produção, com o amparo do Estado, mesmo que essas precarizem as condições de vida do trabalhador (ANTUNES, 2000).

Esse quadro de mudanças das relações entre capital e trabalho refletese em todos os setores da indústria e em todos os países que fazem parte da estratégia de reprodução do sistema produtor de mercadorias.

A partir dos anos 1990, a indústria da construção civil também vai utilizar instrumentos oferecidos pela lógica flexível de diminuição do custo da força de trabalho, entre os quais, o fim do alojamento.

O setor adapta-se de forma diferenciada às transformações ocorridas no direito trabalhista e às estratégias de diminuição do custo da força de trabalho. Antes da regulamentação do alojamento, em 1995, sua implementação era vantajosa, pois não apresentava alto custo de construção, garantia o acesso de trabalhadores migrantes como força de trabalho barata, além de permitir que o operário estivesse à disposição da obra. A partir de 1995, com as exigências de melhorias nas condições dos alojamentos e o consequente aumento do custo da força de trabalho, o setor da construção civil, antes mesmo de qualquer processo formal de desregulamentação por parte do Estado, descarta o alojamento. Assim, as melhorias não chegam a se efetivar, valendo-se o setor de outros expedientes.

\section{Notas}

1 - Ver SPOLLE, Marcus V. "O fim do alojamento na construção civil: uma 'porta de entrada' a menos para o migrante na metrópole", dissertação de mestrado defendida, em 2001, no Programa de Pós-Graduação em Geografia Humana da FFLCH-USP.

2 - O conceito de "acumulação flexível" ou "especialização flexível" foi pioneiramente desenvolvido por Sabel e Piore em The Second Industrial Divide (1984).

3 - Em média, a construção de um edifício residencial demora de seis meses a um ano e meio, segundo informações coletadas em entrevista com representante do Sindicato dos Empregados da Construção Civil.

4 - É importante salientar que foi utilizado o termo "recente" para um corte temporal de dois anos de residência na cidade ou na grande São Paulo.

\section{Referências}

ANTUNES, Ricardo. Adeus ao trabalho. São Paulo: Cortez, 2000.

GRANDI, Sonia Lemos. Desenvolvimento da indústria da construção no Brasil: mobilidade e acumulação do capital e da Força de Trabalho. Tese em Ciências Sociais/FFLCH. São Paulo: USP, 1985. 
KURZ, Robert. Os últimos combates. Petrópolis: Vozes, 1997.

MINISTÉRIO DO TRABALHO - FUNDACENTRO - SST/Mtb. Norma Regulamentadora 18 Condições e Meio Ambiente do Trabalho na Indústria da Construção - Histórico sobre a alteração da Nova NR18/ Reunião Tripartite/ Portaria 4, de 4.7.95, publicada no D.O.U. em 7.7.95.

SABEL, C. e PIORE, M. The Second Industrial Divide. Nova lorque: Basic Books, 1984.

SPOLLE, Marcus Vinicius. O fim do alojamento na construção civil: uma "porta de entrada" a menos para o migrante na metrópole. Dissertação em Geografia Humana/Dpto. de Geografia/FFLCH, São Paulo: USP, 2001.

\title{
RESUMO
}

Até a década de 1980, o alojamento era considerado a "porta de entrada" do migrante na cidade. Porém, a partir da década de 1990, a indústria da construção civil passa a não utilizálo com frequência, o que remeteu à investigação das causas e consequências do fim do uso desse instrumento de aliciamento, controle e exploração capitalista, na reprodução da força de trabalho do migrante dentro da metrópole. $O$ artigo trata, ainda, da relação entre o fim do alojamento e o processo de flexibilização da produção capitalista, como um dos instrumentos de desregulamentação dos direitos trabalhistas, ou a antecipação da desregulamentação formal.

Palavras-chave: mobilidade da força de trabalho; migração; alojamento na indústria da construção civil.

\begin{abstract}
Until the decade of 1980s, accommodations made for civil construction workers were considered as a gate of entrance for migrants in the city. The article tries to elucidate the reasons for the end of this practice, which was a tool for enticements, control and capitalist exploration, and its consequences in the reproduction of the migrant work force in the metropolis. The end of this kind of accommodation for the workers is considered in its connection to flexibilization practices in capitalist production, as well as a way of suppressing worker rights.
\end{abstract}

Keywords: mobility of the workforce; migration; accommodation in the construction industry. 